\title{
Alterations in Disc Height, Foraminal Height and Foraminal Width Following One and Two Level AxiaLIF ${ }^{\circledR}$ - A Radiological Analysis
}

Nitin Kukkar', Ashim Gupta1,2, Devraj Banerjee ${ }^{1}$, Neru Bedi', Benjamin J Main²,3 and Per Freitag ${ }^{\text {1* }}$

${ }^{1}$ Division of Orthopaedics and Rehabilitation, Department of Internal Medicine, Southern Illinois University School of Medicine, Springfield, IL, USA

${ }^{2}$ Department of Medical Microbiology, Immunology \& Cell Biology, Southern Illinois University, School of Medicine, Springfield, IL, USA

${ }^{3}$ University of Illinois at Springfield, Springfield, IL, USA

\section{Abstract}

Design: Retrospective linear radiological analysis study.

Objective: To investigate the effects of $\mathrm{AxiaLIF}^{\circledR}$ on anterior disc height $(\mathrm{ADH})$, posterior disc height $(\mathrm{PDH})$, foraminal height $(\mathrm{FH})$ and foraminal width $(\mathrm{FW})$ and demonstrate that $A x i a L I F^{\circledR}$ is an effective minimally-invasive surgery technique for indirect decompression and restoration of disc height.

Background: Degenerative changes of the lumbar motion segment often lead to stenosis of the spinal canal or neuroforamen. AxiaLIF ${ }^{\oplus}$ is intended to indirectly increase and stabilize foraminal dimensions by restoring disc height in patients with degenerative disc disease, thereby relieving the axial and radicular pain.

Method: Retrospective study of patients who underwent a $360^{\circ}$ lumbar interbody fusion at L4-5 and L5-S1 with

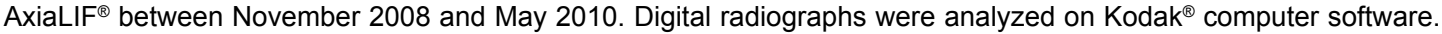
$\mathrm{ADH}, \mathrm{PDH}, \mathrm{FH}$, and FW, were measured. The anterior vertebral height of L5 vertebra was used to calibrate distance and eliminate potential magnification error for each radiograph.

Results: Our study exhibited a mean increase in PDH and ADH at L4-5 and L5-S1 with 2-level AxiaLIF®. Similarly, a mean increase was observed in FH at L5-S1 and FW at L4-5 and L5-S1 with 2-level AxiaLIF ${ }^{\circledR}$. All changes were statistically significant. The change in $\mathrm{FW}$ and $\mathrm{FH}$ were even more pronounced with 1-level AxiaLIF ${ }^{\circledR}$, with a comparable change in posterior and anterior disc height (DH).

Conclusion: AxiaLIF ${ }^{\circledR}$ acts to reduce instability by decreasing motion and fusing segments, thus reducing the dynamic compression of nerve roots and cauda equina. We conclude that XxiaLIF $^{\circledR}$ is comparable to anterior lumbar interbody fusion (ALIF) and transforaminal lumbar interbody fusion (TLIF) in terms of indirect decompression and increased $\mathrm{DH}$, with the added benefit of preserving the annulus, anterior longitudinal ligament, and posterior longitudinal ligament. Further observations are required to accurately assess whether AxiaLIF ${ }^{\circledR}$ maintains fusion and preserves disc and foraminal area long term.

Keywords: AxiaLIF; Spine; Disc height; Foraminal height; Foraminal width; Surgery

Abbreviations: ADH: Anterior Disc Height; PDH: Posterior Disc Height; FH: Foraminal Height; FW: Foraminal Width; DH: Posterior and Anterior Disc Height; ALIF: Anterior Lumbar Interbody Fusion; TLIF: Transforaminal Lumbar Interbody Fusion; LBP: Lower Back Pain; CT: Computed Tomography; MRI: Magnetic Resonance Imaging; VBH: Anterior L5 Vertebral Height

\section{Introduction}

Back pain is a fairly common problem in the US and occurs in both young adults as well as older individuals. Causes of back pain can be varied and range from degenerative disc disease to lumbar canal stenosis. Lumbar fusion is the current gold standard for recalcitrant low back pain (LBP) not responding to conservative management. Thus, there should be no surprise that in the last decade, the number of lumbar fusions performed has significantly increased. In 2001, the Swedish Lumbar Spine Study Group demonstrated that lumbar fusion provided relief for disabling back pain better than that of conservative treatment $[1,2]$. The results of this prospective randomized study are promising, but the question that remains is which fusion technique provides the most efficient means for spine fusion? Interbody arthrodesis using autografts, allografts, or cages exhibits efficient lumbar fusion and has been observed to effectively reduce lower back pain and provide immediate structural support [3].

The lowermost two levels of lumbar spine (i.e. L4-L5 and L5S1) contribute most to the motion as well as normal lordosis of lumbar spine [4]. Thus, not surprisingly, these levels are also most commonly degenerate, effectively leading to back and radicular pain due to compression of the neuroforamen. These degenerative changes frequently result in stenosis of the spinal canal or neuroforamen [5-7]. The decrease in disc height caused by degeneration not only alters the shape of the neuroforamen, but will also significantly reduce the height of the foramen [8]. This decrease in PDH and FH is associated with foraminal nerve root compression [9].

AxiaLIF" (TranS1, Inc., Wilmington, NC) has been developed as a minimally-invasive option for decompression and fusion at these two levels of lumbar spine (i.e. L4-L5 and L5-S1). AxiaLIF is an interbody device to be implanted through a paracoccygeal approach. This device is fairly new and was approved by FDA in 2004 for L5- S1 and in May 2008 for L4-S1 fusion to be used only in conjunction with a posterior fixation device such as pedicle screws or facet screws. It has been shown that $\mathrm{FH}$ decreases by an average of $6.5 \mathrm{~mm}$ after disc removal

*Corresponding author: Per Freitag, Division of Orthopedics and Rehabilitation, Southern Illinois University, School of Medicine, P.O. Box 19679, Springfield, IL 62794-9679, USA, Tel: (217) 545-8865; Fax: (217) 5457901; E-mail: agupta@siumed.edu

Received September 26, 2013; Accepted December 18, 2013; Published December 21, 2013

Citation: Kukkar N, Gupta A, Banerjee D, Bedi N, Main BJ (2013) Alterations in Disc Height, Foraminal Height and Foraminal Width Following One and Two Level AxiaLIF ${ }^{\circledR}$ - A Radiological Analysis. J Spine S5: 008. doi:10.4172/2165-7939.S5008

Copyright: $\odot 2013$ Kukkar N, et al. This is an open-access article distributed under the terms of the Creative Commons Attribution License, which permits unrestricted use, distribution, and reproduction in any medium, provided the original author and source are credited. 
[10]. AxiaLIF" is intended for patients suffering from degenerative disc disease and works by stabilizing the dimensions of the foramen, thus relieving axial and radicular pain.

To the best of our knowledge, no studies have evaluated the effect of AxiaLIF" on DH, FH or FW. The FW changes in relation to facet joint position have also not been studied in the past literature. The objective of this study was to investigate the effect of AxiaLIF on alterations in $\mathrm{ADH}, \mathrm{PDH}, \mathrm{FH}$ and FW. We hypothesize that AxiaLIF is an effective minimally-invasive technique for indirect decompression on neuroforamina and restoration of disc height.

\section{Material and Methods}

Patients who received a $360^{\circ}$ lumbar interbody fusion at L5-S1 and L4-S1 with AxiaLIF between November 2008 and May 2010 were identified. Data was collected as part of a project given an IRB exemption determination. Patients were evaluated for inclusion using roentgenographic, roentgenographic, myelographic, computed tomography (CT) and magnetic resonance imaging (MRI) techniques.

The surgical procedure involved placing the patient on the Jackson table in the prone position with support under the chest and pelvis with minimal flexion of the hips to allow normal lordosis of the lumbar spine. Two C-arms were positioned for simultaneous visualization of the anterior-posterior and lateral views of the lumbar spine, sacrum, and coccyx. A $2 \mathrm{~cm}$ incision next to the coccyx was made, the deep fascia was opened, and a pathway was made to the anterior sacrum pushing the rectum anteriorly from the mesorectal soft tissue plane. The sacral promontory was entered, dilated, the disc material was excised, and crushed cancellous allograft bone graft mixed with iliac crest bone marrow aspirate was replaced. The implant screw was then placed achieving distraction based on the amount of disc collapse prior to surgery. Posterior percutaneous instrumentation (Sextant; Medtronic Sofamor Danek, Memphis, TN) was then placed. The wounds were closed in layers with absorbable suture.

A standard set of $x$-rays were obtained before and after surgery at the 3-month follow-up visit utilizing a standardized protocol. All radiographs were taken with the patient standing and the fists resting on the ipsilateral clavicles or hands grasping rod at level of clavicles. Angulations were measured on digital radiographs via Kodak Software System. Mean values and standard deviations (SD) were then computed for all measurements. Spondylolisthesis was assessed by each investigator using the Meyerding methodology $[11,12]$. The measurements were performed using guidelines previously reported $[4,9]$. Measurements were as follows:

1. Anterior Disc Height - ADH was "measured in the planes of the anterior surfaces of the adjacent vertebral bodies, where the distances between the adjacent superior and inferior end plates were the shortest." [9]

2. Posterior Disc Height- PDH was "measured in the planes of the posterior surfaces of the adjacent vertebral bodies, where the distances between the adjacent superior and inferior end plates were the shortest." [9]

3. Foraminal Height - FH was "measured as the maximum distance between the inferior margin of the pedicle of the superior vertebra and the superior margin of the pedicle of the inferior vertebra." [4]

4. Foraminal Width - FW was "measured as the shortest distance between the superior edge of the superior articular process of the caudal vertebra and the posterior edge of inferior endplate of the cranial vertebra." [4]
5. Anterior L5 vertebral height $(\mathrm{VBH})-\mathrm{VBH}$ was measured as the maximum distance between the superior and inferior margin of L5 vertebra. This was done to account for any potential magnification errors.

\section{Statistical Analysis}

Descriptive statistics were performed on all data elements. For the purpose of standardization and to account for any potential magnification error, the ratio of all the measurements to the anterior L5 vertebral height was used in statistical analysis. Data were reported as the mean \pm SD in percentages of the L5 vertebral height. Independent t-tests were used to compare means between subgroups. Statistical significance was set at a $\mathrm{p}$-value $<0.05$. Data were analyzed using GraphPad Prism version 4.03 (Graph Pad Software, Inc., San Diego, CA USA).

\section{Results}

Eighty-one patients met the inclusion criteria and received a $360^{\circ}$ lumbar interbody fusion at L4-S1 and L5-S1 with AxiaLIF between November 2008 and May 2010. Participants were included in this retrospective study. Patient demographics are presented in Table 1. Twenty-nine patients underwent AxiaLIF 1-Level (L5-S1) and 52 patients underwent AxiaLIF 2 2-Level (L4-S1). The AxiaLIF ${ }^{\circ}$ 1-L group had 15 men and 14 women with a mean age of 45 years (range 25-62). The AxiaLIF 2-L group had a mean age of 47.5 for men and 52 for women, with a combined mean age of 49 years (range 22-89).

Comparison of alterations in $\mathrm{FH}, \mathrm{FW}, \mathrm{ADH}$ and $\mathrm{PDH}$ associated with AxiaLIF 1-L (Figures 1 and 2) and AxiaLIF 2 -L (Figures 2 and

\begin{tabular}{|c|c|c|c|}
\hline & \# of Cases & Average Age (SD) & Age Range \\
\hline All Levels & 81 & $48(14.1)$ & $22-89$ \\
\hline Female & 41 & $50(14.3)$ & $22-89$ \\
\hline Male & 40 & $46(13.8)$ & $23-82$ \\
\hline 1-Level & 29 & $45(12.0)$ & $25-62$ \\
\hline Female & 14 & $46(11.0)$ & $28-62$ \\
\hline Male & 15 & $45(13.2)$ & $25-60$ \\
\hline 2-Level & 52 & $49(15.1)$ & $22-89$ \\
\hline Female & 27 & $52(15.6)$ & $22-89$ \\
\hline Male & 25 & $47(14.3)$ & $23-82$ \\
\hline
\end{tabular}

Table 1: Patient demographics.
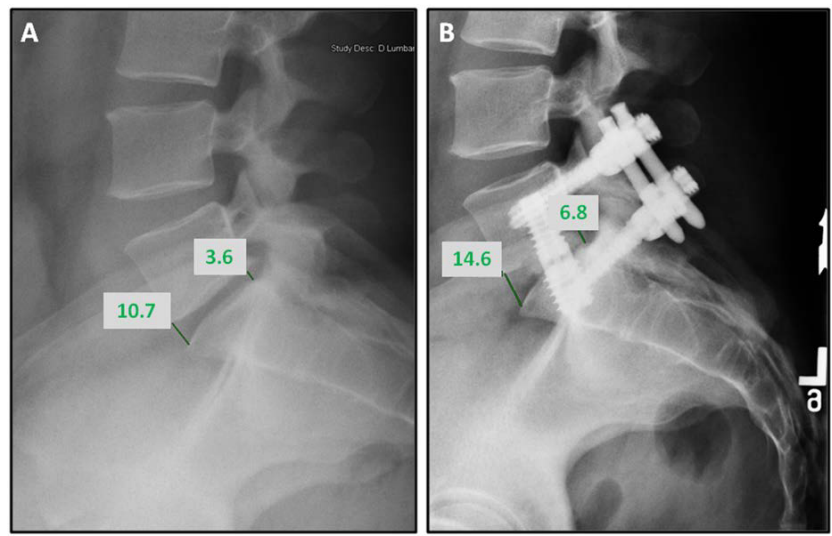

Figure 1: Preoperative and postoperative comparison of anterior and posterior disc height after 1-level AxiaLIF ${ }^{\circledR}$ procedure. 

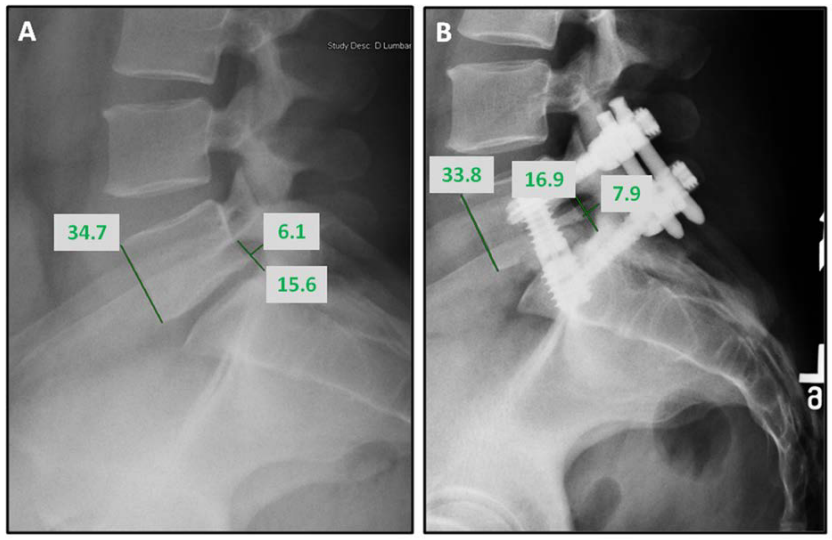

Figure 2: Preoperative and postoperative comparison of foramin height, foramin width, and L-5 vertebral height after 1-level AxiaLIF ${ }^{\circledR}$ procedure.
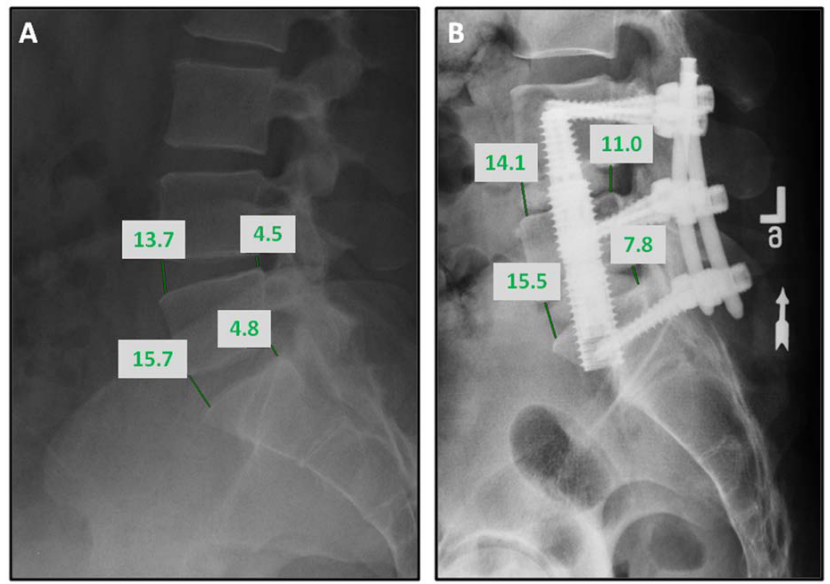

Figure 3: Preoperative and postoperative comparison of anterior and posterior disc height after 2-level AxiaLIF ${ }^{\circledR}$ procedure.

3) was performed and the results are summarized in Tables 2 and 3. The preoperative actual measured value $(\mathrm{mm} \pm \mathrm{SD})$ in the AxiaLIF 1 - $\mathrm{L}$ group were $\mathrm{FH}=18.3 \pm 2.49, \mathrm{FW}=8.2 \pm 1.83, \mathrm{PDH}=4.9 \pm 1.33$ and $\mathrm{ADH}=9.4 \pm 2.99$. Expressed as a percentage of the average L5 VBH, the values were $49.2 \%, 22.0 \%, 13.2 \%$ and $25.3 \%$ for $\mathrm{FH}, \mathrm{FW}, \mathrm{PDH}$ and $\mathrm{ADH}$ respectively. The preoperative actual measured value $(\mathrm{mm} \pm \mathrm{SD})$ in the AxiaLIF* 2-L group at L5-S1 were $\mathrm{FH}=21 \pm 3.15, \mathrm{FW}=9 \pm 2.54 \mathrm{PDH}=6$ \pm 1.97 and $\mathrm{ADH}=9 \pm 2.97$. Expressed as a percentage of the average L5 $\mathrm{VBH}$, the values were $60.0 \%, 25.7 \%, 17.1 \%$ and $25.7 \%$ for $\mathrm{FH}, \mathrm{FW}, \mathrm{PDH}$ and $\mathrm{ADH}$ respectively. The preoperative actual measured value $(\mathrm{mm} \pm$ $\mathrm{SD}$ ) in the AxiaLIF 2 -L group at L4-L5 were $\mathrm{FH}=18 \pm 2.69, \mathrm{FW}=7 \pm$ $2.15, \mathrm{PDH}=5 \pm 1.64$ and $\mathrm{ADH}=10 \pm 2.99$. Expressed as a percentage of the average L5 VBH, the values were $51.4 \%, 20.0 \%, 14.3 \%$ and $28.6 \%$ for $\mathrm{FH}, \mathrm{FW}, \mathrm{PDH}$ and $\mathrm{ADH}$ respectively.

Our study shows that there is a mean increase of $6.54 \% \pm 4.06 \%$ in $\mathrm{PDH}$ at $\mathrm{L} 4-5$ and $5.27 \% \pm 5.98 \%$ in $\mathrm{ADH}$ at $\mathrm{L} 4-\mathrm{L} 5$ and $\mathrm{PDH}$ mean increase of $5.02 \% \pm 4.24 \%$ and $4.58 \% \pm 6.18 \%$ in $\mathrm{ADH}$ at L5-S1 in 2-level AxiaLIF cases. These changes are significant at L4-L5 and L5S1 for PDH respectively and at L4-L5 and L5-S1 for ADH respectively. Similarly the mean change in $\mathrm{FH}$ was $7.40 \% \pm 6.25 \%$ at L4-L5 and $5.28 \%$ $\pm 5.37 \%$ at L5-S1 in 2-levels AxiaLIF. The mean change in FW at L4-L5 was $5.23 \% \pm 5.39 \%$ and $5.81 \% \pm 5.35 \%$ at L5-S1 in 2-levels AxiaLIF. As before, these changes were statistically significant (statistics performed with actual corrected ratios) with p-values of 0.000 and 0.000 for $\mathrm{FH}$ at L4-L5 and L5-S1 and for FW at L4-L5 and L5-S1. The change in FW and $\mathrm{FH}$ was even more pronounced with single level AxiaLIF with the change in $\mathrm{DH}$ being comparable. In this group, the mean change in $\mathrm{PDH}$ was $5.93 \% \pm 2.83 \%$, the $\mathrm{ADH}$ change was $4.84 \% \pm 5.39 \%$, the average change in $\mathrm{FH}$ was $7.28 \% \pm 3.38 \%$, and mean change in FW was $5.63 \pm 3.42 \%$. True to the 2-level findings, the p-values were calculated to be $0.000,0.000,0.000$, and 0.000 for $\mathrm{PDH}, \mathrm{ADH}, \mathrm{FH}$, and $\mathrm{FW}$ for L5-S1 respectively.

\section{Discussion}

Anatomical disparities or degenerative changes of the intervertebral foramen may affect $\mathrm{FH}$ and $\mathrm{FW}$, causing foraminal narrowing or stenosis. Disc degeneration effects FH and FW [9,13-16] moreover, by reducing spinal stability, disc degeneration may affect dynamic alteration in foraminal dimensions. The largest neural structures located within the intervertebral foramina of the lumbar spine are the dorsal root ganglia. There is a significant correlation between the foraminal and nerve-root cross sectional areas, and the ratios of these cross-sectional areas are larger at the inferior lumbar levels [9]. Furthermore large nerve roots located at inferior lumbar interspaces are more likely to be affected by foraminal constriction [17].

Typically, adequate space is available between nerve root ganglia and the ligamentum flavum. However foramen shape is altered by disc degeneration [18] and foraminal constriction may result in the entrapment of nerve root ganglia. Moreover PDH is significantly reduced in the patients with nerve root compression group compared to non-compressed group. Mayoux-Benhamou et al. also suggested that a $4 \mathrm{~mm}$ disc collapse significantly reduces the diameter of the foramen [8]. $\mathrm{FH}$ of was observed to decrease by $16 \%$ in flexion and $13 \%$ in extension and FW was observed to decrease by $30 \%$ in flexion and $16 \%$ in extension, respectively [8]. Therefore, increases in disc and foraminal

\begin{tabular}{|c|c|c|c|c|c|}
\hline & $\begin{array}{c}\text { Mean } \pm \text { SD } \\
(\mathrm{mm})\end{array}$ & $\begin{array}{l}\text { Magnification- } \\
\text { Corrected } \\
\text { Percentage of } \\
\text { Averaged VBH }\end{array}$ & & $\begin{array}{l}\text { Mean } \pm \text { SD } \\
(\mathrm{mm})\end{array}$ & $\begin{array}{l}\text { Magnification- } \\
\text { Corrected } \\
\text { Percentage of } \\
\text { Averaged VBH }\end{array}$ \\
\hline \multicolumn{3}{|c|}{ Pre-op } & \multicolumn{3}{|c|}{ Post-op } \\
\hline \multicolumn{6}{|c|}{ 1-LEVEL } \\
\hline \multicolumn{6}{|c|}{ L5-S1 } \\
\hline \multicolumn{3}{|c|}{ Averaged VBH $=37.2( \pm 3.30) \mathrm{mm}$} & \multicolumn{3}{|c|}{ Averaged VBH $=37.9( \pm 2.68) \mathrm{mm}$} \\
\hline $\mathrm{FH}$ & $18.3 \pm 2.49$ & $49.2 \%$ & $\mathrm{FH}$ & $21.5 \pm 2.62$ & $56.7 \%$ \\
\hline FW & $8.2 \pm 1.83$ & $22.0 \%$ & FW & $10.4 \pm 1.85$ & $27.4 \%$ \\
\hline $\mathrm{PDH}$ & $4.9 \pm 1.33$ & $13.2 \%$ & $\mathrm{PDH}$ & $7.3 \pm 1.48$ & $19.3 \%$ \\
\hline $\mathrm{ADH}$ & $9.4 \pm 2.99$ & $25.3 \%$ & $\mathrm{ADH}$ & $11.4 \pm 2.81$ & $30.1 \%$ \\
\hline \multicolumn{6}{|c|}{ 2-LEVEL } \\
\hline \multicolumn{6}{|c|}{ L4-L5 } \\
\hline \multicolumn{3}{|c|}{ Averaged VBH $=35( \pm 3.87) \mathrm{mm}$} & \multicolumn{3}{|c|}{ Averaged VBH $=37( \pm 2.97) \mathrm{mm}$} \\
\hline $\mathrm{FH}$ & $21 \pm 3.15$ & $60.0 \%$ & $\mathrm{FH}$ & $24 \pm 3.24$ & $64.9 \%$ \\
\hline FW & $9 \pm 2.54$ & $25.7 \%$ & FW & $12 \pm 1.99$ & $32.4 \%$ \\
\hline $\mathrm{PDH}$ & $6 \pm 1.97$ & $17.1 \%$ & $\mathrm{PDH}$ & $8 \pm 2.24$ & $21.6 \%$ \\
\hline $\mathrm{ADH}$ & $9 \pm 2.97$ & $25.7 \%$ & $\mathrm{ADH}$ & $11 \pm 2.99$ & $29.7 \%$ \\
\hline \multicolumn{6}{|c|}{ L5-S1 } \\
\hline \multicolumn{3}{|c|}{ Averaged VBH $=35( \pm 3.87) \mathrm{mm}$} & \multicolumn{3}{|c|}{ Averaged VBH $=37( \pm 2.97) \mathrm{mm}$} \\
\hline $\mathrm{FH}$ & $18 \pm 2.69$ & $51.4 \%$ & $\mathrm{FH}$ & $21 \pm 2.87$ & $56.8 \%$ \\
\hline FW & $7 \pm 2.15$ & $20.0 \%$ & FW & $10 \pm 2.22$ & $27.0 \%$ \\
\hline $\mathrm{PDH}$ & $5 \pm 1.64$ & $14.3 \%$ & $\mathrm{PDH}$ & $7 \pm 1.84$ & $18.9 \%$ \\
\hline $\mathrm{ADH}$ & $10 \pm 2.99$ & $28.6 \%$ & $\mathrm{ADH}$ & $12 \pm 2.80$ & $32.4 \%$ \\
\hline
\end{tabular}

Table 2: Results of ADH, PDH, FH, and FW after AxiaLIF ${ }^{\circledR}$ 1-Level and 2-Level. 
Citation: Kukkar N, Gupta A, Banerjee D, Bedi N, Main BJ (2013) Alterations in Disc Height, Foraminal Height and Foraminal Width Following One and Two Level AxiaLIF® - A Radiological Analysis. J Spine S5: 008. doi:10.4172/2165-7939.S5-008

Page 4 of 5

\begin{tabular}{|c|c|c|c|c|c|}
\hline & $\mathbf{n}$ & $\begin{array}{l}\text { Pre-op Value } \pm \text { SD } \\
\text { (Corrected Value) }\end{array}$ & $\begin{array}{l}\text { Post-op Value } \pm \text { SD } \\
\text { (Corrected Ratio) }\end{array}$ & Percent Changed (\%) & P-Value \\
\hline \multicolumn{6}{|c|}{ 1-Level } \\
\hline FH @ L5-S1 & 29 & $0.495 \pm 0.0725$ & $0.5679 \pm 0.0728$ & 12.8 & $<0.001$ \\
\hline FW @ L5-S1 & 29 & $0.21958 \pm 0.04726$ & $0.27584 \pm 0.05318$ & 20.1 & $<0.001$ \\
\hline PDH @ L5-S1 & 29 & $0.13393 \pm 0.03913$ & $0.19321 \pm 0.04035$ & 30.9 & $<0.001$ \\
\hline ADH @ L5-S1 & 29 & $0.2532 \pm 0.0805$ & $0.3016 \pm 0.0727$ & 15.9 & $<0.001$ \\
\hline \multicolumn{6}{|c|}{ 2-Level } \\
\hline FH @ L4-L5 & 52 & $0.5929 \pm 0.0897$ & $0.6669 \pm 0.0957$ & 10.8 & $<0.001$ \\
\hline FW @ L4-L5 & 52 & $0.26927 \pm 0.06901$ & $0.32157 \pm 0.06009$ & 15.9 & $<0.001$ \\
\hline PDH @ L4-L5 & 52 & $0.15860 \pm 0.05662$ & $0.22398 \pm 0.06423$ & 28.7 & $<0.001$ \\
\hline ADH @ L4-L5 & 52 & $0.2470 \pm 0.0867$ & $0.2997 \pm 0.0854$ & 17.3 & $<0.001$ \\
\hline FH @ L5-S1 & 52 & $0.5113 \pm 0.0931$ & $0.5641 \pm 0.0836$ & 9.3 & $<0.001$ \\
\hline FW @ L5-S1 & 52 & $0.20299 \pm 0.05984$ & $0.26105 \pm 0.05975$ & 21.4 & $<0.001$ \\
\hline PDH @ L5-S1 & 52 & $0.15065 \pm 0.04846$ & $0.20088 \pm 0.05409$ & 23.7 & $<0.001$ \\
\hline ADH @ L5-S1 & 52 & $0.2806 \pm 0.0903$ & $0.3264 \pm 0.0857$ & 13.3 & $<0.001$ \\
\hline
\end{tabular}

Table 3: Statistical analysis of AxiaLIF ${ }^{\circledR}$ 1-Level and 2-Level.
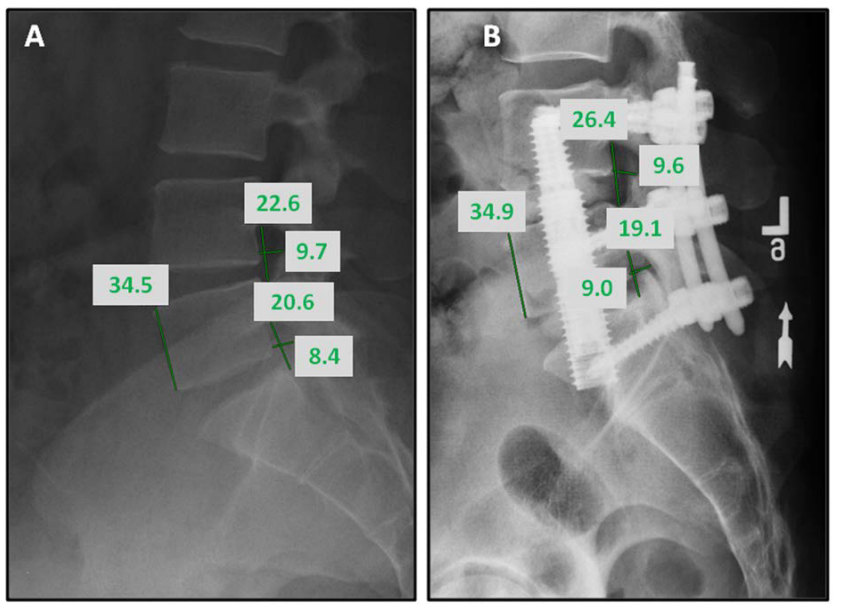

Figure 4: Preoperative and postoperative comparison of foramin height, foramin width, and L-5 vertebral height after 2-level AxiaLIF ${ }^{\circledR}$ procedure

height are more effective in reducing the back and radicular pain at the lowermost 2 levels of spine (i.e. L4-L5 and L5-S1). In a cadaveric study on the ideal amount of lumbar foraminal distraction for pedicle screw instrumentation, the greatest incremental changes in foraminal height and area were noted at $6 \mathrm{~mm}$ of distraction [15]. In our study the average corrected change in FH in both 1 and 2 level AxiaLIF" groups was significant and averaged approximately of $7 \%$. We also found a statistically significant change in FW. These findings suggest an increase in available space for nerve roots. Correlating the values of our studies to above mentioned studies we conclude that AxiaLIF may provide adequate distraction for an indirect decompression.

Hsieh et al. reviewed medical records and radiographs of 32 patients who underwent ALIF and 25 patients who underwent TLIF from 2000 to 2004 [19]. Their results indicated that ALIF was superior to TLIF in its capacity to restore $\mathrm{FH}$, local disc angle, and lumbar lordosis, with similar improvement in postoperative visual analogue scale scores [19]. ALIF increased FH by $18.5 \%(2.7 \mathrm{~mm})$ and PDH by $2.2 \mathrm{~mm}$, whereas TLIF decreased FH by $0.4 \%(0.5 \mathrm{~mm})$ and increased PDH by $1.2 \mathrm{~mm}$ by TLIF [19]. Therefore the results of our study are almost equivalent with ALIF group of this study in terms of disc and foraminal height change with combined change of $14.4 \%$ in $\mathrm{FH}$ and $11 \%$ in PDH. Furthermore AxiaLIF' was radiographically comparable to anterior lumbar interbody fusion (ALIF) in terms of indirect decompression and observed disc height. The results of our study also correspond well to the results of other devices such as posterior interspinous device which increase $\mathrm{FH}$ to produce relief of symptoms and have been shown to be accompanied with clinical benefits [20].

AxiaLIF $^{\circ}$ relies on distraction, and few prior studies have analyzed how distraction influences the intervertebral space and the foraminal area. Schlegel et al. reported that anterior interbody distraction increased the foraminal space in their cadaveric study [21]. In their study, wooden intradiscal spacers used to distract spinal motion segments increased foraminal area by $14.8 \%$ and $37.2 \%$ with $5 \mathrm{~mm}$ and $10 \mathrm{~mm}$ of distraction, respectively [21]. Similarly, Chen et al reported that the BAK (Spinetech Inc., Minneapolis, MN) interbody fusion system can increase neuroforaminal volume, and when applied anteriorly in the L4-L5 and L5-S1 segments the BAK system produced a $29.0 \%$ and $33.8 \%$ increase in the foraminal area at L4-L5 and L5-S1, respectively [22]. AxiaLIF is a similar biomechanical device and our results indicate that it increases the $\mathrm{FH}$ and $\mathrm{FW}$; therefore the foraminal area, and potentially volume, for nerve roots and makes AxiaLIF perform similar to intradiscal spacers or interbody cages in terms of efficacy to cause indirect decompression by distraction. 
Citation: Kukkar N, Gupta A, Banerjee D, Bedi N, Main BJ (2013) Alterations in Disc Height, Foraminal Height and Foraminal Width Following One and Two Level AxiaLIF® - A Radiological Analysis. J Spine S5: 008. doi:10.4172/2165-7939.S5-008

Page 5 of 5

The current study presents strengths and limitations. To our knowledge, this is the first study in which the effects of AxiaLIF" on foraminal and disc dimensions have been analyzed. Technically, the foraminal dimensions were calculated on radiographs and not CT scans or MRI, however we measured the L5 VBH to rule out the confounding variable of magnification error. Second, measurement of foraminal area was not done; it is difficult to accurately calculate this due to the large variation in foraminal shape between levels and subjects. That being said, it is difficult to assess whether changes in foraminal area per se drastically affect nerve root ganglia. Additionally, the assessment of the sagittal dimensions of the foramen allows accounting for the effect of bulging of soft tissues, including the posterior annulus, ligamentum flavum, vertebral body translation (spondylolisthesis) and facet joint capsules on the reduction of the foraminal dimension. Thirdly, it is a retrospective study for a small patient group on a radiological analysis. This, we feel, is a real limitation of this short radiographic study and a prospective mid to long follow-up study to evaluate the long term change in radiological and clinical parameters is essential to evaluate the performance of AxiaLIF.

In conclusion, degenerative changes as well as instability in the lumbar spine cause a decrease in neuroforaminal area accompanied with decrease in disc height. AxiaLIF' is an effective minimally-invasive device that increases disc height and neuroforaminal area by distraction. It has a supplementary advantage of reducing instability by decreasing the motion and eventually fusing the segments, thus reducing the dynamic compression of nerve roots and cauda equina. The results are equivalent to ALIF and TLIF as shown in previous studies. However, AxiaLIF" exhibits the added benefit of preserving the annulus, anterior longitudinal ligament, and posterior longitudinal ligament. Further long term follow-up studies are required to accurately judge the results of the implant at achieving and maintaining fusion to preserve this increase in disc and foraminal area.

\section{Ethics}

Data was collected as part of a project given an IRB exemption determination.

The views expressed in this article are those of the author and do not necessarily reflect the official policy or position of the Air Force, the Department of Defense or the U.S. Government.

\section{References}

1. Fritzell P, Hagg O, Wessberg P, Nordwall A (2001) 2001 Volvo Award Winner in Clinical Studies: Lumbar fusion versus nonsurgical treatment for chronic low back pain: a multicenter randomized controlled trial from the Swedish Lumbar Spine Study Group. Spine (Phila Pa 1976) 26: 2521-2532.

2. Fritzell $P$, Hägg $O$, Wessberg $P$, Nordwall $A$; Swedish Lumbar Spine Study Group (2002) Chronic low back pain and fusion: a comparison of three surgical techniques: a prospective multicenter randomized study from the Swedish lumbar spine study group. Spine (Phila Pa 1976) 27: 1131-1141.

3. Burkus JK, Schuler TC, Gornet MF, Zdeblick TA (2004) Anterior lumbar interbody fusion for the management of chronic lower back pain: current strategies and concepts. Orthop Clin North Am 35: 25-32.
4. Korovessis PG, Stamatakis MV, Baikousis AG (1998) Reciprocal angulation of vertebral bodies in the sagittal plane in an asymptomatic Greek population. Spine (Phila Pa 1976) 23: 700-704.

5. Sato K, Kikuchi S (1993) An anatomic study of foraminal nerve root lesions in the lumbar spine. Spine (Phila Pa 1976) 18: 2246-2251.

6. Sohn HM, You JW, Lee JY (2004) The relationship between disc degeneration and morphologic changes in the intervertebral foramen of the cervical spine: a cadaveric MRI and CT study. J Korean Med Sci 19: 101-106.

7. Vernon-Roberts B, Pirie CJ (1977) Degenerative changes in the intervertebra discs of the lumbar spine and their sequelae. Rheumatol Rehabil 16: 13-21.

8. Mayoux-Benhamou MA, Revel M, Aaron C, Chomette G, Amor B (1989) A morphometric study of the lumbar foramen. Influence of flexion-extension movements and of isolated disc collapse. Surg Radiol Anat 11: 97-102.

9. Hasegawa T, An HS, Haughton VM, Nowicki BH (1995) Lumbar foramina stenosis: critical heights of the intervertebral discs and foramina. A cryomicrotome study in cadavera. J Bone Joint Surg Am 77: 32-38.

10. Cinotti G, De Santis P, Nofroni I, Postacchini F (2002) Stenosis of lumba intervertebral foramen: anatomic study on predisposing factors. Spine (Phila Pa 1976) 27: 223-229.

11. Marchetti PG, Binazzi R, Briccoli A, Vaccari V, Borelli $P$, et al. (1994) The surgical treatment of spondylolisthesis. Chir Organi Mov 79: 85-91.

12. MEYERDING HW (1956) Spondylolisthesis; surgical fusion of lumbosacral portion of spinal column and interarticular facets; use of autogenous bone grafts for relief of disabling backache. J Int Coll Surg 26: 566-591.

13. Crock HV (1981) Normal and pathological anatomy of the lumbar spinal nerve root canals. J Bone Joint Surg Br 63B: 487-490.

14. Vanderlinden RG (1984) Subarticular entrapment of the dorsal root ganglion as a cause of sciatic pain. Spine (Phila Pa 1976) 9: 19-22.

15. Infusa A, An HS, Glover JM, McGrady L, Lim TH, et al. (1996) The ideal amount of lumbar foraminal distraction for pedicle screw instrumentation. Spine (Phila Pa 1976) 21: 2218-2223.

16. Jenis LG, An HS (2000) Spine update. Lumbar foraminal stenosis. Spine (Phila $\mathrm{Pa}$ 1976) 25: 389-394.

17. Bose K, Balasubramaniam $P$ (1984) Nerve root canals of the lumbar spine Spine (Phila Pa 1976) 9: 16-18.

18. Stephens MM, Evans JH, O'Brien JP (1991) Lumbar intervertebral foramens. An in vitro study of their shape in relation to intervertebral disc pathology. Spine (Phila Pa 1976) 16: 525-529.

19. Hsieh PC, Koski TR, O'Shaughnessy BA, Sugrue P, Salehi S, et al (2007) Anterior lumbar interbody fusion in comparison with transforaminal lumbar interbody fusion: implications for the restoration of foraminal height, local disc angle, lumbar lordosis, and sagittal balance. J Neurosurg Spine 7: 379-386.

20. Lazaro BC, Brasiliense LB, Sawa AG, Reyes PM, Theodore N, et al. (2010) Biomechanics of a novel minimally invasive lumbar interspinous spacer: effects on kinematics, facet loads, and foramen height. Neurosurgery 66: 126-132.

21. Schlegel JD, Champine J, Taylor MS, Watson JT, Champine M, et al. (1994) The role of distraction in improving the space available in the lumbar stenotic canal and foramen. Spine (Phila Pa 1976) 19: 2041-2047.

22. Chen D, Fay LA, Lok J, Yuan P, Edwards WT, et al. (1995) Increasing neuroforaminal volume by anterior interbody distraction in degenerative lumbar spine. Spine (Phila Pa 1976) 20: 74-79.
This article was originally published in a special issue, Minimally Invasive Spine Surgery handled by Editor. Dr. Hiroshi Kuroki, University of Miyazaki, Japan 